\title{
INVESTIGATION OF THE PROCESS OF METHANE-OXYGEN COMBUSTION IN STEAM UNDER THE ATMOSPHERIC PRESSURE
}

\author{
Pribaturin N.A. ${ }^{1}$, Bogomolov A.R. ${ }^{1}$, Azikhanov S.S. ${ }^{2}$, and Shevyrev S.A ${ }^{3 \text {, a }}$ \\ ${ }^{1}$ Kutateladze Institute of Thermophysics SB RAS, Novosibirsk, Russia \\ ${ }^{2}$ Kuzbass State Technical University named after T.F. Gorbachev, Kemerovo, Russia \\ ${ }^{3}$ National Research Tomsk Polytechnic University, 634050 Tomsk, Russia
}

\begin{abstract}
In the article presented results of combustion methane-oxygen mixtures in the slightly superheated water steam under the atmospheric pressure. It is shown that exist dependence of flow rate combustible mixture and steam ratio $\left(G_{\text {g.s. }} / G_{s}\right)$ on the composition of the reacting mixture at the outlet of combustion chamber. There is a trend of increasing $\mathrm{CO}_{2}$ concentration in the reacting mixture at the outlet of combustion chamber with increase of $G_{g . s .} / G_{s}$.
\end{abstract}

\section{Introduction}

Since the $60 \mathrm{~s}$ of the last century, the important period of turbine construction started; it was characterized by production of condensation and cogeneration turbines for supercritical steam parameters: $23.5 \mathrm{MPa}$ and $560^{\circ} \mathrm{C}$. The turbines for supercritical steam parameters operate with rotation frequency $n=50 \mathrm{c}^{-1}$. These turbines are intended for both thermal power stations (TPS) on organic fuel and atomic power plants (APP).

When considering the influence of the individual steam parameters on the efficiency (increasing the absolute efficiency) of Rankine cycle, it is often replaced by the equivalent Carnot cycle. Heat is removed in a condenser in wet steam at constant temperature $T_{2}$; this coincides with the terms of the Carnot cycle. The heat is supplied at three sites, and this can be represented as the product of some equivalent temperature $T_{e}$ and entropy difference $S_{2}-S_{1}$. Obviously, equivalent temperature $T_{e}$ can be obtained if the Rankine cycle efficiency is equated to the Carnot cycle efficiency:

$$
\eta_{t}=\eta_{k}=\frac{T_{e}-T_{2}}{T_{e}}, \text { then } T_{e}=\frac{T_{2}}{1-\eta_{t}} .
$$

One of the most effective methods for increasing the efficiency of the heat cycle is an increase in the temperature of live steam, as it follows from the above equation. To ensure the reliable operation for the required long period with increasing temperature, we should turn from simple carbon steel to heat-resistant steels, especially for the heating surfaces of superheater, live steam lines and details of the turbine head. Thus, almost all power plants are mainly calculated for the work with the initial steam temperature not higher than $540-565^{\circ} \mathrm{C}$; although until the $80 \mathrm{~s}$ of the last century several installations were made for $600-650^{\circ} \mathrm{C}$. Surprisingly, A.V. Scheglyaev [1] has supposed already in 1976 that the desire to improve the heat cycle efficiency would raise again the question about increasing the initial temperature of steam.

Last decade, there are relatively productive works on live steam overheating just before the turbine. The authors of [2-3] suggest to superheat steam in the combustion chamber or hydrogen superheater to combust hydrogen and oxygen of stoichiometric composition in the flow of live steam; this can significantly increase the steam temperature at the turbine inlet from $560-600^{\circ} \mathrm{C}$ to $1500-1700^{\circ} \mathrm{C}$. This cannot be achieved at combustion of fossil fuels in traditional steam boilers because with a rise of temperature at a certain level, the yield and strength points of modern steels decrease drastically and creep deformation occurs.

Analysis of characteristics of environmentally responsible production of electricity using hydrogen for steam superheating showed that if we use electricity generated by a hydro power plant, take into account the cost of liquid hydrogen production and its safe storage and transportation to power plants, the electrical efficiency does not exceed 0.37 [2], although the efficient use of disposable heat difference is ensured due to a set of technical solutions [3].

To reduce the cost of expensive fuel in the form of hydrogen and oxygen for steam superheating, we can use methane. Since natural gas is mainly composed of methane (up to 98\%), its burning hardly produces by-products or their amounts are much smaller than in the case of other fossil fuels. The direction, associated with the development of technology of steam overheating

\footnotetext{
${ }^{\text {a }}$ Corresponding author: barom@mail.kuzstu.ru
} 


\section{EPJ Web of Conferences}

with the direct use of the products of methane-oxygen mixture combustion, is being developed actively now, for instance see [4, 5].

Methane combustion occurs according to the following reactions:

$$
\begin{aligned}
& \mathrm{CH}_{4}+2 \mathrm{O}_{2}=\mathrm{CO}_{2}+2 \mathrm{H}_{2} \mathrm{O}, \Delta H=-802 \mathrm{~kJ} / \mathrm{mole} \\
& \mathrm{CH}_{4}+\mathrm{O}_{2}=\mathrm{CO}+\mathrm{H}_{2} \mathrm{O}+\mathrm{H}_{2}, \Delta H=-277,4 \mathrm{~kJ} / \mathrm{mole} \\
& \mathrm{CH}_{4}+0,5 \mathrm{O}_{2}=\mathrm{CO}+2 \mathrm{H}_{2}, \Delta H=-35,6 \mathrm{~kJ} / \mathrm{mole}
\end{aligned}
$$

The methane-oxygen mixture in the combustion products and residual methane in steam generate the conditions for methane steam reforming at the temperatures of above $700^{\circ} \mathrm{C}$ even without a catalyst:

$$
\mathrm{CH}_{4}+\mathrm{H}_{2} \mathrm{O}=\mathrm{CO}+3 \mathrm{H}_{2}, \Delta H=206,4 \mathrm{~kJ} / \mathrm{mole} .
$$
[6]:

However, considering this, under the above conditions, $\mathrm{H}_{2} \mathrm{O}$ (steam) can interact with formed $\mathrm{CO}$ (steam conversion of $\mathrm{CO}$ )

$$
\mathrm{CO}+\mathrm{H}_{2} \mathrm{O}=\mathrm{CO}_{2}+\mathrm{H}_{2}, \Delta H=-41 \mathrm{~kJ} / \mathrm{mole}
$$

Therefore, hydrocarbon oxidation, in particular, methane is more complex in comparison with hydrogen and carbon dioxide, and this does not give the clear ideas about the real kinetic mechanism of reactions.

\section{Experiments and results discussion}

The research is aimed at determination of the conditions for sustainable combustion of a combustible mixture in steam under the atmospheric pressure with the live steam temperature of about $150^{\circ} \mathrm{C}$ and composition of the combustion products depending on the ratio of metering characteristics of the fuel mixture and steam. The scheme of experimental setup for studying the regimes of methane/oxygen combustion in the atmosphere low-temperature steam with production of high-temperature steam is shown in Figure 1.

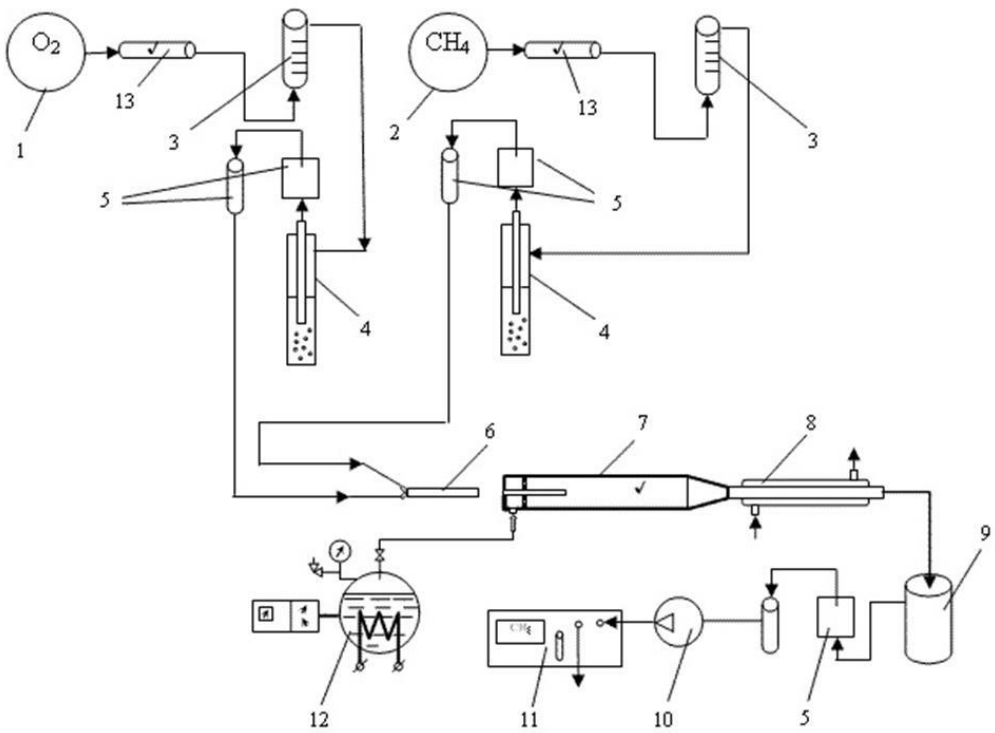

Figure 1. Scheme of experimental setup: 1 - tank with $\mathrm{O} 2 ; 2$ - tank with $\mathrm{CH} 4 ; 3$ - gas flow meters; 4 - flame arrester; 5 - vessels for gas drying; 6 - gas burner; 7 - steam superheater (combustion chamber); 8 - condenser; 9 - vessel for separation of gaseous and liquid products; 10 compressor; 11 - gas analyzer; 12 - steam generator; 13 - gas temperature sensor.

Due to mixing the combustion products and steam in superheater 7 the superheated steam $\left(480-815^{\circ} \mathrm{C}\right)$ with some admixtures was obtained under the atmospheric pressure. Then, the gas mixture passed through condenser-separator 8 , where steam was condensed, and is was fed though moisture separator 9 to flow gas analyzer 11. The measurement error for component concentrations did not exceed 5\%. The length of steam superheater was $200 \mathrm{~mm}$, its inner diameter was $20 \mathrm{~mm}$, and it was made 
of stainless steel. In the experiments, the following parameters were controlled: flow rate and temperature of combustible mixture components at the reactor inlet, flow rate and temperature of steam, temperature, volume and concentration of outgoing gases. These parameters were registered automatically.

Data obtained (Figure 2) testify an increase in $\mathrm{CO}_{2}$ concentration and a decrease in $\mathrm{H}_{2}$ concentration in the range of combustible mixture $\left(\mathrm{CH}_{4}+\mathrm{O}_{2}\right)$-stem ratios $\mathrm{G}_{\text {g.s. }} / \mathrm{G}_{\mathrm{s}}=0.26-0.45$. The coefficient of oxidizer excess varied within $\alpha=0.87-1.05$. The values of Re criterion in the nozzle of a channel for combustible mixture were 2015-2638, at that, stable combustion was observed.

With an increase in the relative mass flow rate in the studied range, the temperature of the reacting media increases from 670 to $815^{\circ} \mathrm{C}$. At that, reactions (1) and (5) occur primarily towards the product formation, on the assumption of occurring reactions (2) and (3), which created the conditions for reaction (5). Since there is no methane in the reaction mixture at low residual oxygen content (from 0.2 to $1.2 \%$ ), steam reforming occurs presumably by reaction (4).

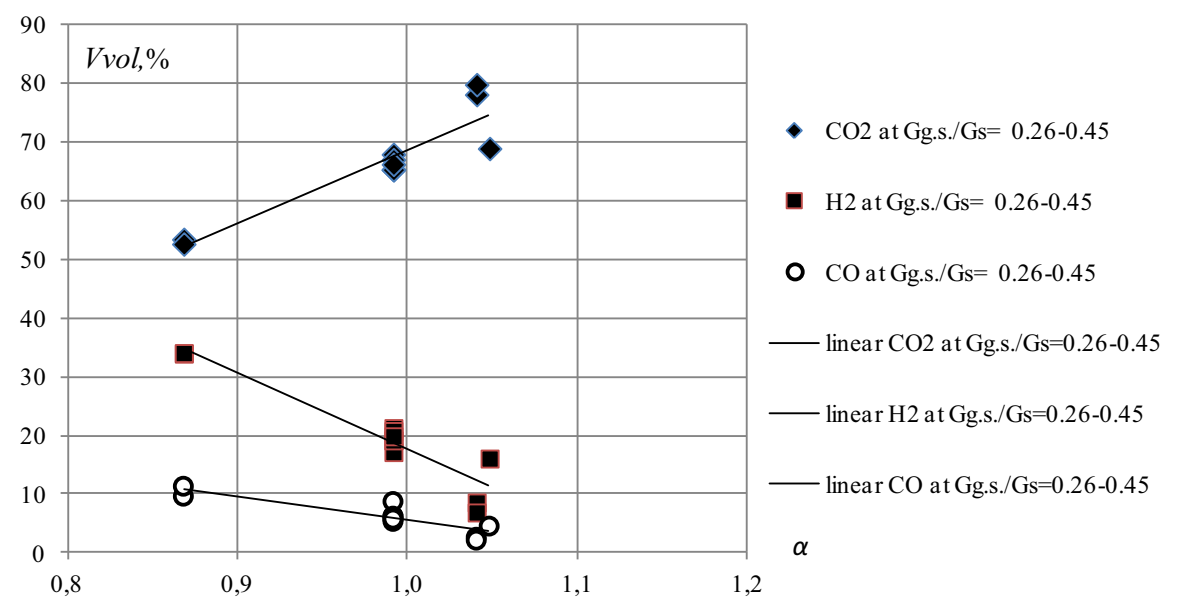

Figure 2. Dependence of a change in composition of the reacting mixture at the outlet of combustion chamber on coefficient of oxidizer excess $\alpha$ in the range of mass ratios of combustible mixture and steam flow rates $G_{g . s .} / G_{s}=0.26-0.45$.

\section{Conclusions}

1) The conditions for stable combustion of methane-oxygen mixture in the stream flow and composition of the reaction products were studied.

2) The trend to a change in composition of the products of reacting media towards maximal formation of carbon dioxide is shown.

3) Further studies are needed to determine the conditions under which a reduction in $\mathrm{H}_{2}$ concentration occurs, to improve the safety of steam turbines.

The research was financially supported by the Russian Ministry of Education and Science; unique identifier for applied research (project) RFMEFI57614X0049.

\section{References}

1. A. V. Scheglyaev, Steam Turbines (The Theory of Heat Process and Turbine Construction) (Moscow: Energiya, 1976)

2. B. A. Shifrin, Proc. of Russian National Conference on Heat Transfer-4, 1, 266 (2014)

3. A.V. Fedorov, O.O. Milman, B.A. Shifrin, High-performance technologies of electricity production using the organic and hydrogen fuel, Moscow. MSTU, (2007), 115.

4. Zou Chun, Song Yu, Li Guoyuan, Cao Shiying, He Yizhuo, Zheng Chuguagn,

5. X. Gu, S. S. Zang, B. Ge, Exp Fluids, 41, 826 (2006)

6. O.V. Krylov, Rossiyskiy Khimicheskiy Zhurnal, XLIV (1), 19(2000) 